\title{
Hirschsprung's Disease in An Adult Male - An Unusual Presentation
}

\author{
Bhabani Sankar Sahoo $^{1}$, Rajat Karma ${ }^{2}$, Shipra Singhal ${ }^{3}$, Arun Chhetri ${ }^{4}$ \\ ${ }^{1}$ Department of General Surgery, Vardhman Mahavir Medical College \& Safdarjung Hospital, New Delhi, India \\ ${ }^{2}$ Department of Surgical Oncology, Vardhman Mahavir Medical College \& Safdarjung Hospital, New Delhi, India \\ ${ }^{3}$ Department of Pathology, Vardhman Mahavir Medical College \& Safdarjung Hospital, New Delhi, India \\ ${ }^{1}$ Department of General Surgery, Vardhman Mahavir Medical College \& Safdarjung Hospital, New Delhi, India
}

\begin{abstract}
Hirschsprung's Disease (HD) is a rare congenital disease where aganglionosis of the submucosal \& myenteric neural plexuses principally affects the rectosigmoid or rectal segments of varying length. The vast majority of cases of HD are recognized in newborns or infants but a few cases with a milder form elude surgery until adolescence or adulthood. HD in adult is a rare \& misdiagnosed cause of long-standing refractory constipation. We report a case of $\mathrm{HD}$ in a 32 year old man who presented to the emergency department with absolute constipation, severe abdominal distension \& features consistent with large bowel obstruction. Operative findings were suggestive of $\mathrm{HD}$, recto-colonic resection \& diversion colostomy was done and diagnosis was confirmed as colonic aganglionosis on biopsy. The diagnosis of $\mathrm{HD}$ in adult is difficult due to the rarity of the disease \& the incidence of short \& ultra short disease with mild symptoms. The patients with long standing history of undiagnosed constipation since infancy \& childhood could be suffering from HD. HD should be suspected in adults with a chronic history of constipation. Whenever reasonable doubt is present, biopsies should be taken.
\end{abstract}

Keywords: Hirschsprung's disease; chronic constipation; aganglionosis; adult; Duhamel procedure; negative calretinin staining

\section{Introduction}

Hirschsprung's disease (HD) is a congenital disorder in which there is complete aganglionosis in both the submucosal and myenteric plexus. It principally affects the rectosigmoid or the rectal segments. It is a rare pathology affecting about 1 in 5000 births and majority of the cases are diagnosed in the neonatal period ${ }^{[1]}$. It is a cause of bowel obstruction in children, but in rare circumstances, the disease is diagnosed in adulthood ${ }^{[2-5]}$.A diagnosis of adult HD is made when the patient is older than the age of 10 years at the time of diagnosis ${ }^{[5]}$. Only about 550 cases have been reported in English literature since $1950^{[6]}$. In most cases, the patient have mild form of disease and remain undiagnosed early in their lives because the proximal innervated colon can be hypertrophied and thus compensates for the distal narrowed, obstructed, aganglionic segment(S100 positive; calretinin negative $)^{[2,7,8,9,10]}$. In addition, the patients often try to relieve the constipation by administration of enema. Eventually, the colon can no longer propel the stool forward and the patient will present with constipation or fecal retention, and very rarely present in obstruction.

We report a case of aganglionosis in a 32 year old male who developed massive distension of abdomen and absolute constipation and was treated with recto-colonic resection and diversion colostomy.

The work has been reported in line with the SCARE criteria $^{[11]}$.

\section{Literature Survey}

The first ever recorded case of HD was reported by Frederick Ruysch who published an autopsy report in 1691 entitled "Enormis intestini coli filatatio". Whitehouse and Kernohan documented the absence of ganglions in the Meissner and myentric plexus ${ }^{[12]}$ which led to development of effective surgical treatment by Swenson and Bill in 1948. Adult HD was first reported by Rosin in 1950 in a 54-yearold physician with a short aganglionic segment ${ }^{[13]}$. HD affects approximately 1 in 5000 live births and usually presents in infancy and early childhood, though the exact incidence of the disease is not known in adults. Only a small number remain undetected after the age of 5 years ${ }^{[1]}$. After Rosin, some 300 cases have appeared in literature, with at least some features of adult or adolescent HD, some of which have been proven on biopsy. Fairgrieve ${ }^{[2]}$ documented HD in 7 men whose age varied from 17 to 34 years. All the patients had shorts segment disease. Two of the patients just had a massively dilated rectum with no demonstrable constriction. Anuras et al ${ }^{[4]}$, in 1984 reported 4 cases with biopsy proven HD but only 2 had rectal narrowing. Recently Miyatomo ${ }^{[5]}$ reported a 23 year old male with chronic constipation for whom semi emergency colostomy was made.

The most commonly accepted theory after studies on human embryos and fetuses suggests that the primary pathology is the result of defective migration of ganglion precursors of the neural crest cell into the hindgut 1 which occurs during 12 weeks of gestation. This results in complete absence of ganglion cell in the submucosal (Meissner's) and myentric (Auerbach's) plexuses. Molecular studies have linked HD to defects in the neural crest cell function ${ }^{[14]}$. The aganglionic segment remains persistently contracted due to an 


\section{International Journal of Science and Research (IJSR) \\ ISSN (Online): 2319-7064}

Index Copernicus Value (2016): 79.57 | Impact Factor (2015): 6.391

unopposed sympathetic action whereas the proximal normal segment retains its peristaltic function. As a result there is work hypertrophy eventually dilation (Mega colon), rarely even perforation of the normally innervated $\operatorname{colon}^{[1]}$. Other proposed mechanisms include defects in the differentiation of neuroblasts in the ganglion cells and accelerated ganglion cell destruction in the intestine. More than eight genetic mutations have been identified with the disease. The RET proto-oncogene is most affected and accounts for $50 \%$ of the familial and $20 \%$ of the sporadic cases. Certain RET protooncogene polymorphisms are associated with a phenotype of short or long segment Hirschsprung's disease. Hirschsprung's disease is associated with other chromosomal abnormalities and syndromes such as trisomy 21, cardiac diseases, Congenital aganglionic megacolon congenital hypoventilation syndrome, MEN2, Waardenburg syndrome, and the Smith-Opitz syndrome ${ }^{[15]}$.

\section{Problem Definition}

A diagnosis of adult HD is made if a patient is older than arbitrary age of 10 years at the time of diagnosis. Rich reported a case of newly diagnosed HD in a 74 year old patient. Thus in an age span of 10 to 73 all the patients of long standing history of undiagnosed constipation since infancy and childhood could be suffering from HD. Male: female ratio $4: 1$, and average age of presentation is 24.1 years, half the patients are younger than 30 years $^{[16,17,18,19,20]}$. Other symptoms include abdominal distension, discomfort, and abdominal pain. Only $1.8 \%$ of patients present with complaints of complete non passage of stool and flatus (absolute constipation) ${ }^{[6]}$.

\section{Methodology}

A 32 year old male patient reported to the emergency department at our institute with complaints of absolute constipation since 5 days. He had complaints of constipation since his childhood. The patient, a chronic alcoholic, was being treated in the department of medicine for chronic liver disease, was prescribed laxatives and enema by his attending physician as part of the treatment. The patient used to get partial relief after enema, but during this instance he could not pass stools and continued to have a sensation of abdominal fullness, and stopped passing both stool and flatus since 5 days. He had received enema twice in previous two days, but had no improvement in his symptoms. The patient had persistent sensation of nausea throughout and one episode of vomiting which was non-bilious and contained food particles (from his previous meal). The patient had no similar complaint during childhood. History about delayed meconium passage was not available. The patient had one previous admission for treatment of liver ailment but no previous admission or investigation for any bowel complaint.
On physical examination, the patient was severely emaciated with significant abdominal distension. The patient had persistent tachycardia and bile in nasogastric tube. The abdomen had visible peristalsis and tympanic note on percussion. Digital rectal examination revealed empty rectum and anal canal without any fecal staining. A preoperative $\mathrm{x}$-ray abdomen showed dilated loops with large colonic gas shadows. Preoperative diagnosis of complete large bowel obstruction secondary to colonic growth or volvulus was suspected. Laboratory investigations showed microcytic anaemia and raised blood urea. The general condition of the patient was too sick to allow colonoscopy or computed tomography, so patient was prepared for exploratory laparotomy.

After a brief period of resuscitation, he was taken up for exploratory laparotomy. Intraoperatively, sigmoid colon and distal part of descending colon were massively dilated. The transverse colon, the splenic flexure and a $15 \mathrm{~cm}$ segment of the proximal descending colon appeared to be normal with minimal dilatation. The dilated sigmoid colon had a smooth tapering (transition zone, fig. 1), ending in stricturous segment of about $4 \mathrm{~cm}$ length located near the rectosigmoid junction. The mesentery of dilated large bowel segment had dilated vessels with collaterals implying this distension to be a chronic phenomenon. The mesentery of the sigmoid colon had normal length, thus, excluding volvulus which could have undergone derotation (fig. 2). The dilated portion of the descending colon, sigmoid colon, the rectosigmoid junction and $3 \mathrm{~cm}$ of the proximal rectum was resected, distal stump was closed and proximal colon was exteriorized and specimen was sent for histopathological confirmation.

The gross examination showed massively dilated large colon, measuring $36 \mathrm{~cm}$ in length. The proximal resected end and the distal resected end measured $3.5 \mathrm{~cm}$ and $12 \mathrm{~cm}$ in diameter, respectively. The sections examined showed absence of ganglion cells (Calretinin negative, fig - 3) with presence of hypertrophic nerve bundles (S100 positive. fig. 4(IHC-10X); fig. 5 (IHC-40X)) in the distal resected end. Sections from the proximal dilated end showed presence of ganglion cells (fig. 6) in the myenteric plexus. The intervening bowel wall showed presence of ganglion cells in the myenteric plexus.

The patient had an uneventful postoperative period, the colostomy became functional on postoperative day 2 , orally feeds were started on the same day (postoperative day 2). The patient was discharged on the post operative day 7 after establishment of adequate oral intake with plan of elective colonic pull through (Duhamel procedure).

After 8 weeks, patient underwent colonic pull through and has improved quality of life after follow up of 1 year. 
International Journal of Science and Research (IJSR)

ISSN (Online): 2319-7064

Index Copernicus Value (2016): 79.57 | Impact Factor (2015): 6.391

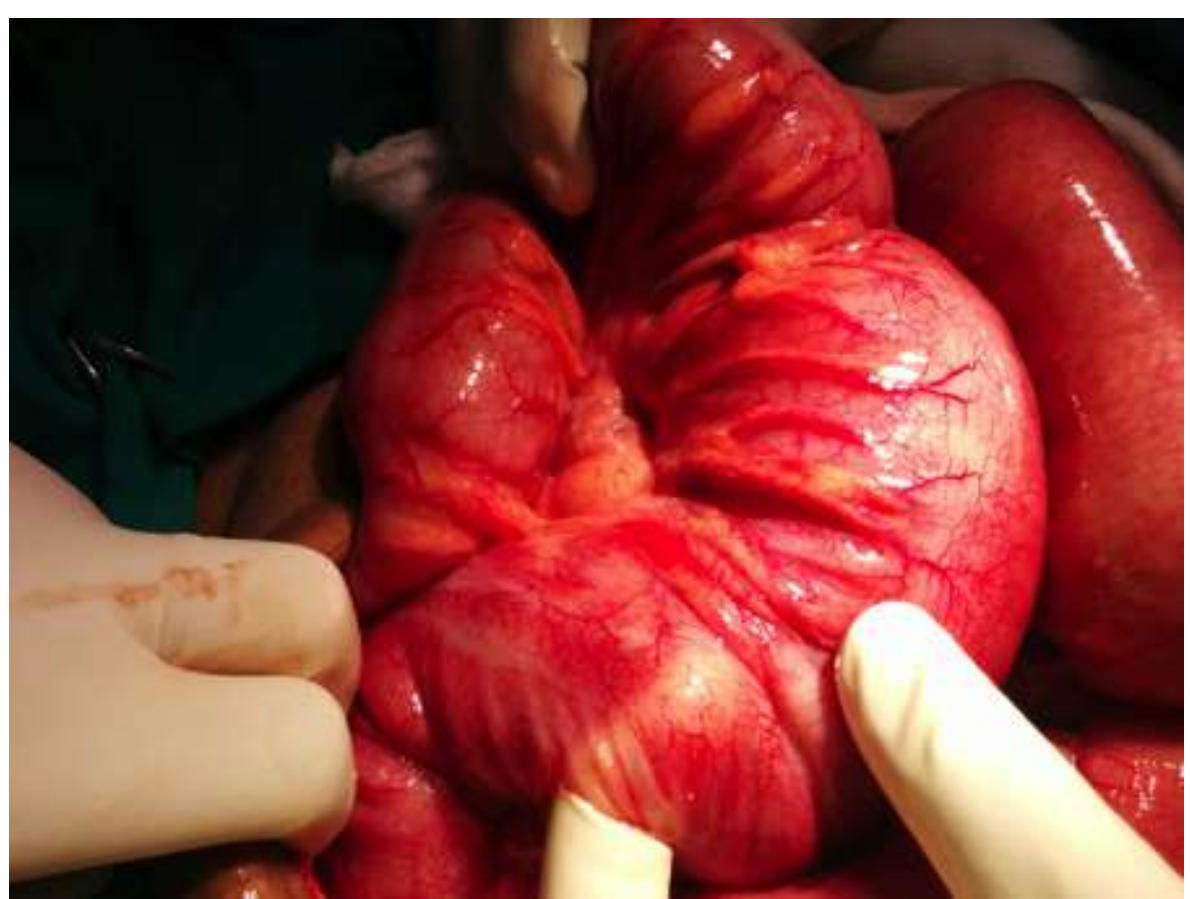

Figure 1: Intraoperative photograph showing transition zone.

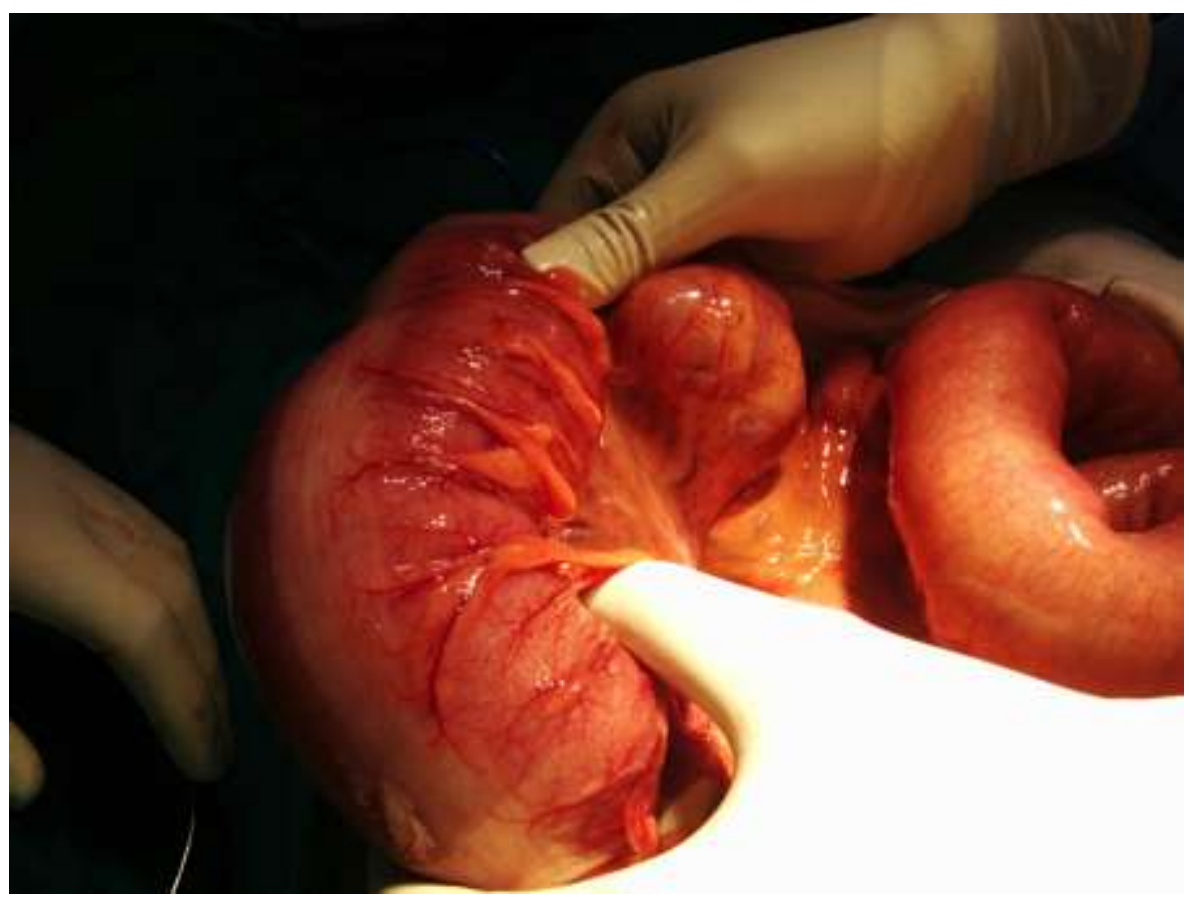

Figure 2: Features of chronic dilatation in mesentery, intraoperatively.

Volume 6 Issue 12, December 2017

www.ijsr.net

Licensed Under Creative Commons Attribution CC BY 
International Journal of Science and Research (IJSR)

ISSN (Online): 2319-7064

Index Copernicus Value (2016): 79.57 | Impact Factor (2015): 6.391

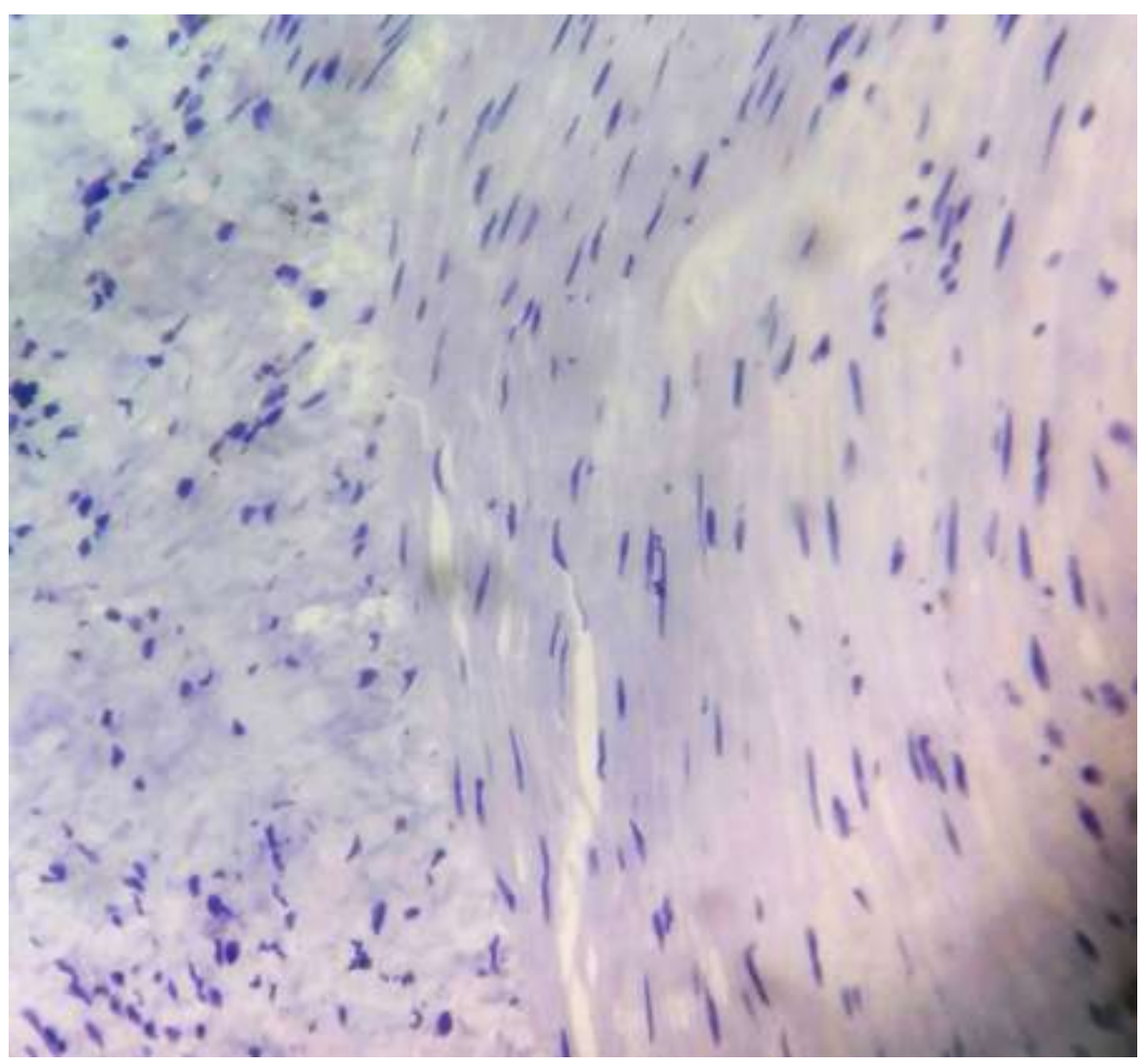

Figure 3: Bowel wall showing absent ganglion cells (calretinin negative, IHC)

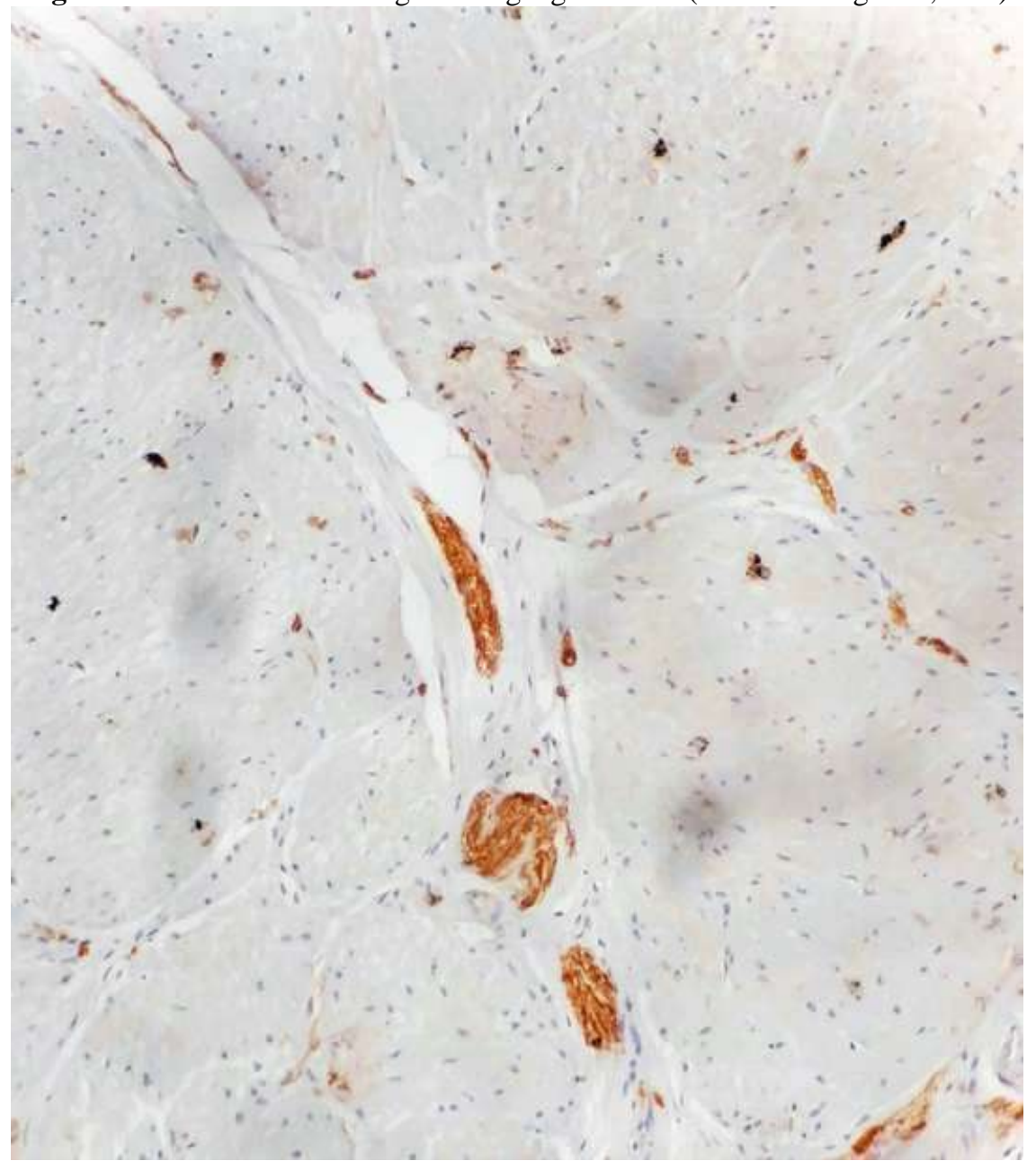

Figure 4: Hypertrophic nerve bundle in distal resected end (S100, IHC-10x) 


\section{International Journal of Science and Research (IJSR)}

ISSN (Online): 2319-7064

Index Copernicus Value (2016): 79.57 | Impact Factor (2015): 6.391

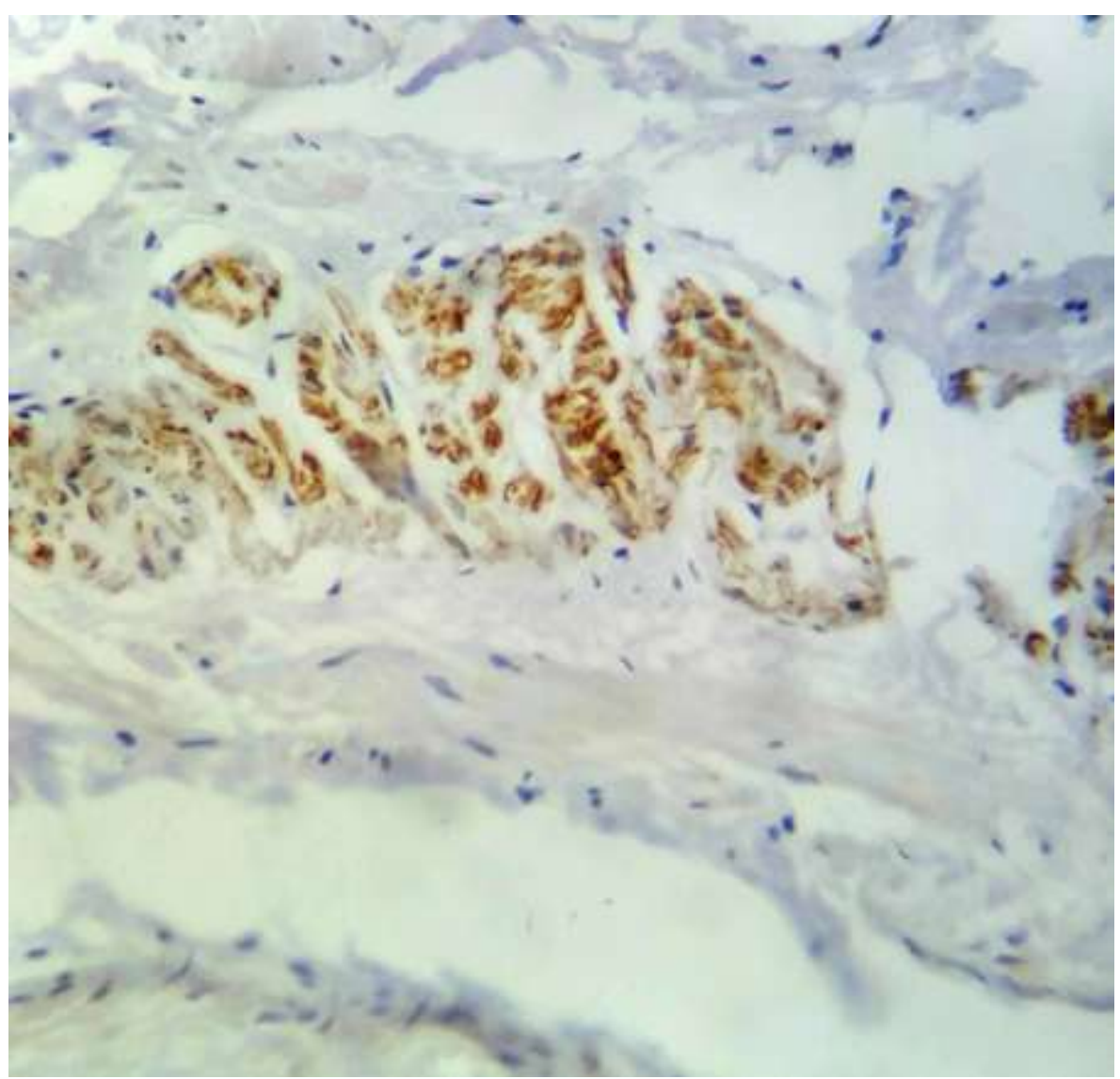

Figure 5: Hypertrophic nerve bundle in distal resected end (S100, IHC- 40x)

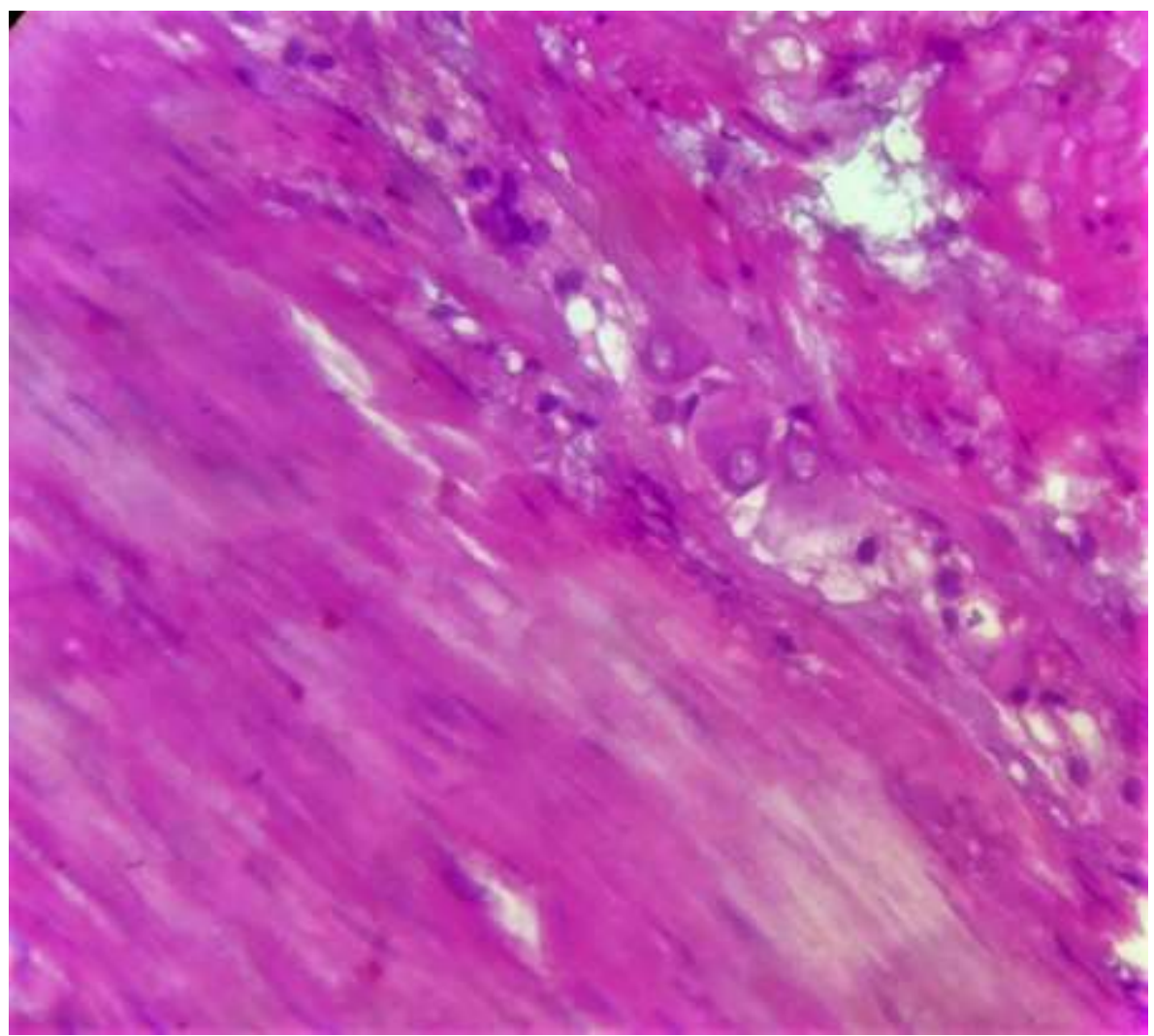

Figure 6: Ganglion cells seen in proximal resected end

\section{Discussion}

The definitive diagnosis of HD rests on rectal biopsy. The initial step in diagnosis described barium enema study in many literatures. A clear cut zone of transition between the aganglionic distal segment which is narrow or of normal caliber and the dilated proximal segment with normal colon is not always visible and in many patients with mild form of

Volume 6 Issue 12, December 2017

www.ijsr.net

Licensed Under Creative Commons Attribution CC BY 


\section{International Journal of Science and Research (IJSR) \\ ISSN (Online): 2319-7064}

Index Copernicus Value (2016): 79.57 | Impact Factor (2015): 6.391

disease the zone may be missed. The transition zone to the dilated segment is characterized as "funnel shaped" or "inverted cone" shape. The transition zone when observed the study is usually stopped because of the potential to cause impaction in the proximal bowel. Though this is a reliable sign, non visualization does not rule out the disease. Rectal narrowing on barium enema is seen in three quarter of the cases $^{[19]}$, but a dilated colon without this zone of rectal narrowing is seen may be seen in ultra short form of HD (less than $5 \mathrm{~cm})^{[21]}$. The dye also may not reach the proximal dilated part unless the bowel is prepared properly. Conventional radiographs may demonstrate findings seen in other small bowel obstructions such as variable gaseous bowel distention, often with air fluid levels. However, the colon is very difficult to differentiate and gas is usually absent the rectum ${ }^{[22]}$. Barium enema led to diagnosis in $84.3 \%$ of Vorobyov's patients ${ }^{[23]}$. Computed tomography scan is, therefore, more useful for better anatomic delineation of the whole colon and anorectal canal, also the changes in colonic girth are better appreciated. Anorectal manometry, typically, shows no internal anal sphincter relaxation in response to rectal distension - recto anal inhibitory response (RAIR). This test has, but, a high false negative rate. The diagnosis is, therefore, always confirmed on biopsy. A full thickness biopsy of the narrowed segment shows absence of ganglion cell, hyperplasia and hypertrophy of the nerve fiber, and increased levels of enzyme acetylcholinesterase. Absence of calretinin stain and positive S100 staining is seen in aganglionic segments ${ }^{[10]}$. Rectal suction biopsy provided inadequate sample in a third of the samples $^{[24]}$.

The diagnosis of HD in adult can be much more difficult than the diagnosis in early infancy. This is due to the rarity of the disease and the incidence of short and ultra short disease with mild symptoms. When the patient has uncommon symptoms and is already undergoing treatment for some misdiagnosed disease the diagnosis becomes even more difficult (as was in our patient). Rectal biopsies are performed only when more common causes have been ruled out. Constipation and acquired megacolon are seen in neoplasm, volvulus, stricture, Chagas disease, anatomical or functional outlet obstruction. Whenever reasonable doubt is present biopsies can be sought for. Alagumuthu reported 3 new cases of adult HD revealed by a volvulus of the sigmoid $^{[25]}$. This goes to show some cases continue to get misdiagnosed and put down to more common causes (like volvulus) and the true pathology remains untreated in the patient.

When surgery is performed in an elective setting with proper work up of the patient, single step surgery can be performed. If the patient has short segment disease or an ultra short segment disease the patient can undergo colo-rectal resection and colonic pull through. In long segment disease and in patients with pan-colonic dilation, total colectomy is advised. In an emergency setup, the patient can be planned for a single stage colonic pull through but a two stage procedure with proximal colostomy and pull through, later, is usually preferred.

\section{Conclusion}

We report a case of HD in adult and emphasize the typical clinical manifestations, massive dilation of colon with rectal narrowing a diagnosis which must be kept in mind is that of HD. This diagnosis is usually overlooked or misdiagnosed in adult patients particularly in the patients with ultra short disease and in presence of medical comorbidities which can cause constipation. Suspicion and proper diagnosis is necessary as surgical management is effective with satisfactory long term functional results and improved quality of life.

\section{References}

[1] Roy CC, Silverman A, Alagille D: Congenital aganglionic megacolon (Hirschsprung's disease). Pediatric clinical gastroenterology. Pediatric clinical gastroenterology. St. Louis (Mo). 1995, 7:503-15.

[2] J. Fairgrieve: Hirschsprung's disease in the adult. Br J Surg. 1963, 1:506-14. 10.1002/bjs.18005022307

[3] Lesser PB, El-Nahas AM, Lukl P, Andrews P, Schuler JG, Filtzer HS: Adult-onset Hirschsprung's disease. JAMA. 1979, 24:747-8. 10.1001/jama.1979.03300080045025

[4] Anuras S, Hade JE, Soffer E, Lu CC, Loening-Baucke V, Soper RT, et al: Natural history of adult Hirschsprung's disease. Jun. 1984, 6:205-10.

[5] Miyamoto M, Egami K, Maeda S, Ohkawa K, Tanaka N, Uchida E, et al.: Hirschsprung's disease in adults: report of a case and review of the literature. J Nippon Med Sch. 2005, 72:113-20. http://doi.org/10.1272/jnms.72.113

[6] Doodnath R, Puri P: A systemic review and metaanalysis of Hirschprung's disease presenting after childhood. Pediatr Surg Int.. 2010, 26:1107-10. 10.1007/s00383-010-2694-2.

[7] Bentley JF: Some new observations on megacolon in infancy and childhood with special reference to the management of megasigmoid and megarectum. Dis Colon Rectum. 1964 Nov-Dec, 7:462-70.

[8] Ikeda K, Goto S: Diagnosis and treatment of Hirschsprung's disease in Japan. An analysis of 1628 patients. Ann Surg. 1984 Apr, 199:400-5.

[9] Venugopal S, Mancer K,Shandling B: The validity of rectal biopsy in relation to morphology and distribution of ganglion cells. J Pediatr Surg. 1981 Aug, 16:433-7.

[10] Barshack I, Fridman E, Goldberg I, Chowers Y, Kopolovic J: The loss of calretinin expression indicates aganglionosis in Hirschsprung's disease. J Clin Pathol. 2004, 57:712-6. https://doi.org/10.1136/jcp.2004.016030

[11] Agha RA, Fowler AJ, Saetta A, Barai I, Rajmohan S, Orgill DP and the SCARE Group. : The SCARE Statement: Consensus-based surgical case report guidelines. International Journal of Surgery. 2016:180-186.

https://doi.org/10.1016/j.ijsu.2016.08.014

[12] Whitehouse FR, Kernohan JW: Myenteric plexus in congenital megacolon; study of 11 cases. Arch Intern Med (Chic). 1948 Jul, 82:75-111. 


\section{International Journal of Science and Research (IJSR) \\ ISSN (Online): 2319-7064 \\ Index Copernicus Value (2016): 79.57 | Impact Factor (2015): 6.391}

[13] Rosin JD, Bargen JA, Waugh JM: Congenital megacolon of a man 54 years of age: report of case. Proc Staff Meet Mayo Clin. 1950 Dec, 20;25:710-5.

[14] Iwashita T, Kruger GM, Pardal R, Kiel MJ, Morrison SJ: Hirschsprung disease is linked to defects in neural crest stem cell function. Science. 2003 Aug, 15;301:972-6. https://doi.org/10.1126/science.1085649

[15] Bakari AA, Gali BM, Ibrahim AG, Nggada HA, Ali N, Dogo D, et al: Congenital aganglionic megacolon in Nigerian adults: Two case reports and review of the literature. Niger J Clin Pract. 2011, 14:249-52. https://doi.org/10.4103/1119-3077.84032

[16] Swenson O: Follow up on 200 patients treated for Hirschsprung's disease during a ten-year period. Ann Surg. 1957 Oct, 146:706-14.

[17] Maglietta ED: Congenital aganglionic megacolon in adults. A case report. Arch Surg . 1960 Oct, 81:598603.

[18] Barnes PR, Lennard-Jones JE, Hawley PR, Todd IP: Hirschsprung's disease and idiopathic megacolon in adults and adolescents. Gut. 1986 May, 27:534-41.

[19] Luukkonen P, Heikkinen M, Huikuri K, Järvinen H: Adult Hirschsprung's disease. Clinical features and functional outcome after surgery. Dis Colon Rectum. 1990 Jan, 33:65-9.

[20] Chen F, Winston JH, Jain SK, Frankel WL: Hirschsprung's disease in a young adult: report of a case and review of the literature. Ann Diagn Pathol. $2006 \quad$ Dec, 10:347-51. https://doi.org/10.1016/j.anndiagpath.2006.03.017

[21] Crocker NL, Messmer JM: Adult Hirschsprung's disease. Clin Radiol. 1991 Oct, 44:257-9.

[22] Berrocal T, Lamas M, Gutieérrez J, Torres I, Prieto C, del Hoyo ML: Congenital anomalies of the small intestine, colon, and rectum. Radiographics. 1999 Oct, 19:1219-36.

https://doi.org/10.1148/radiographics.19.5.g99se04121 9

[23] Vorobyov GI, Achkasov SI, Biryukov OM : Clinical features' diagnostics and treatment of Hirschsprung's disease in adults. Colorectal Dis. 2010 Dec, 12:12428. https://doi.org/10.1111/j.1463-1318.2009.02031.x

[24] Teitelbaum DH, Coran AG: Hirschsprung's Disease and Related Neuromuscular Disorders of the Intestine. Pediatric Surgery: Sixth Edition. 2:1514-59. 10.1016/B978-0-323-02842-4.50102-9

[25] Alagumuthu M, Jagdish S, Kadambari D: Hirschsprung's disease in adults presenting as sigmoid volvulus: a report of three cases. Trop Gastroenterol. 2011 Oct-Dec, 32:341-3.

\section{Author Profile}

Dr. Bhabani Sankar Sahoo is senior resident at Vardhman Mahavir Medical College and Safdarjung Hospital, New Delhi. He did his post graduation in General Surgery from the same institution and has keen interest in Gastrointestinal surgery.

Dr. Rajat Karma is senior resident at Vardhman Mahavir Medical College and Safdarjung Hospital, New Delhi. He did his post graduation in General Surgery from the same institution and has keen interest in Gastrointestinal surgery and GI Oncology.
Dr. Shipra Singhal is junior resident at Vardhman Mahavir Medical College and Safdarjung Hospital, New Delhi. She is doing her post graduation in Pathology from the same institution.

Dr. Arun Chhetri s senior resident at Vardhman Mahavir Medical College and Safdarjung Hospital, New Delhi. He is pursuing post graduation in General Surgery from the same institution.

Volume 6 Issue 12, December 2017 